\title{
Xq26.2-q26.3 microduplication in two brothers with intellectual disabilities: clinical and molecular characterization
}

\author{
Irene Madrigal ${ }^{1,2}$, Miguel Fernández-Burriel ${ }^{3}$, Laia Rodriguez-Revenga ${ }^{1,2}$, Jose Carlos Cabrera ${ }^{4}$, \\ Milagros Martí ${ }^{4}$, Antonio Mur ${ }^{5}$ and Montserrat Milà ${ }^{1,2}$
}

Partial duplications involving the long arm of the $X$ chromosome are associated with mental retardation, short stature, microcephaly, hypopituitarism and a wide range of physical findings. We identified an inherited Xq26.2-Xq26.3 duplication in two brothers with severe mental retardation, hypotonia, growth delay, craniofacial disproportion and dental malocclusion. Chromosome analysis was normal and multiplex ligation-dependent probe amplification analysis detected duplication on Xq26. Further characterization by array comparative genomic hybridization and quantitative PCR helped to determine proximal and distal duplication breakpoints giving a size of approximately $2.8 \mathrm{Mb}$. The duplication encompasses $24 \mathrm{known}$ genes, including the X-linked mental retardation genes ARHGEF6, PHF6, HPRT1 and SLC9A6. Clinical and molecular characterization of Xq duplications will shed more light into the phenotypic implication of functional disomy of X-chromosome genes. Journal of Human Genetics (2010) 55, 822-826; doi:10.1038/jhg.2010.119; published online 23 September 2010

Keywords: aCGH; ARHGEF6; HPRT1; intellectual disability; PHF6; SLC9A6; Xq26.2-q26.3 duplication

\section{INTRODUCTION}

Molecular bases of X-linked metal retardation (XLMR) are very complex due to its high genetic heterogeneity. The search for nonspecific XLMR genes in clinical practice is expensive, and findings are limited by the small number of families having mutations in the same gene. The general use of multiplex ligation-dependent probe amplification (MLPA) and array comparative genomic hybridization (aCGH) has led to the identification of new submicroscopic rearrangements asssociated with mental retardation (MR), see Shaw-Smith et al. ${ }^{1}$ About $5-10 \%$ of patients with XLMR with or without associated phenotypic features show X-chromosome microdeletions or microduplications responsible for the phenotype. ${ }^{2-5}$ These rearrangements often involve more than one gene, being therefore complicated to establish whether the phenotype results from increase in gene dosage of a single gene or of more than one. The prevalence of Xq duplications is still unknown, and only few have been reported. ${ }^{6-16}$ To date, cryptic duplications encompassing MECP2 gene seem to be the most frequent microduplication syndrome responsible for cognitive impairment in patients with $\mathrm{Xq}$ distal duplications. Approximately $1 \%$ of unexplained XLMR may be caused by MECP2 duplications. ${ }^{5}$ Here we describe the characterization of an inherited 2.8 Mb Xq26.2-q26.3 in two brothers with severe MR, hypotonia, growth delay, craniofacial disproportion and dental malocclusion.

\section{MATERIALS AND METHODS}

Patients

Two brothers of 16 and 20 years of age, born to unaffected parents, were referred to our service for mild MR. In the maternal branch of the family, there was history of miscarriages and a male relative also presenting MR (not available for study). The findings from cytogenetic analysis were normal and those from analysis of FRAXA and FRAXE expansions by PCR showed the presence of normal alleles.

\section{Molecular analyses}

MLPA. MLPA analysis was performed with Salsa P106 kit (MRC-Holland, Amsterdam, the Netherlands) as previously described. ${ }^{3}$

Fluorescence in situ hybridization. Interphase fluorescence in situ hybridization study was performed by using BAC clones from RP11 library (BACPAC Resources) mapping on Xq26.3, as previously described. ${ }^{17}$

Array CGH. The duplication was delineated by using an X-chromosomespecific aCGH. Array production, probe preparation and hybridization were performed at the microarray unit of the Centre for Genomic Regulation (Barcelona, Spain) as described elsewhere. Briefly, the tiling path X-chromosome-specific array consists of $>1600$ genomic BAC clones derived from $\mathrm{X}$ chromosome with a resolution of approximately $100 \mathrm{~kb} .{ }^{2}$ Clones were provided from BACPAC resources and correspond to Array type 32K clone set (NCBI36; https://decipher.sanger.ac.uk/application/arraytype/16?chr=X).

${ }^{1}$ CIBER de Enfermedades Raras (CIBERER), Barcelona, Spain; ${ }^{2}$ Biochemistry and Molecular Genetics Department, Hospital Clínic and IDIBAPS, Barcelona, Spain; ${ }^{3} \mathrm{Hospital}$ de Mérida, Unidad de Investigación, Badajoz, Spain; ${ }^{4}$ Sección de Neurología Pediátrica, Hospital Materno-Infantil de Canarias, Las Palmas de Gran Canaria, Spain and ${ }^{5}$ Sección Neonatología, Servicio Pediatría, Hospital del Mar and Universidad Autónoma de Barcelona, Barcelona, Spain 
Breakpoint mapping by quantitative PCR. To delineate the distal and proximal breakpoints, ARHGEF6 and RBMX copy number was quantified by using quantitative PCR (qPCR) with Power Master Mix PCR SYBR Green (Applied Biosystems, Foster City, CA, USA) on an automated ABI 7300 PCR System (Applied Biosystems). ARHGEF6 and RBMX were amplified with primers $22 \mathrm{~F}$ : 5'-TATGCATGTTTCGGGGACTT-3'， 22R: 5'-AGGGGAAGGACAGAAAAG GA-3', and 1F: 5'-CCGGGCAGTATAAAGTTTGC-3', 1R: 5'-GACAATGGGTT CAAGCTCCA- $3^{\prime}$, respectively. All samples were amplified in triplicates. Relative quantification was performed by standard curve method for quantification against a control amplicon of the ZNF495 gene (F: 5'-CCTTGCAAAGAAC

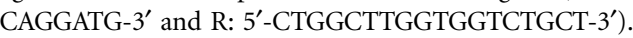

$X$-chromosome inactivation studies. Androgen-receptor $(A R)$ and FMR1 gene methylation assays were performed on lymphocyte genomic DNA as previously described. ${ }^{18,19}$ Skewed alleles were considered when the inactivation percentage was more than $85 \%$.
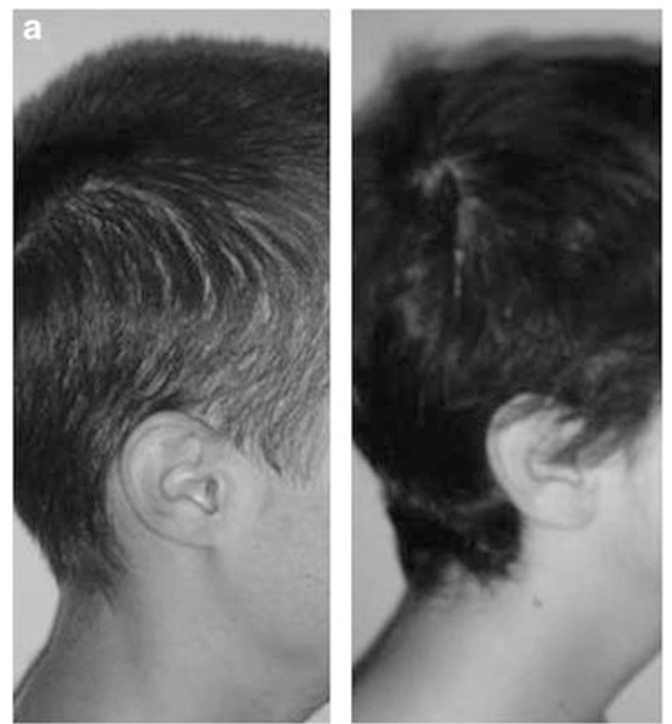
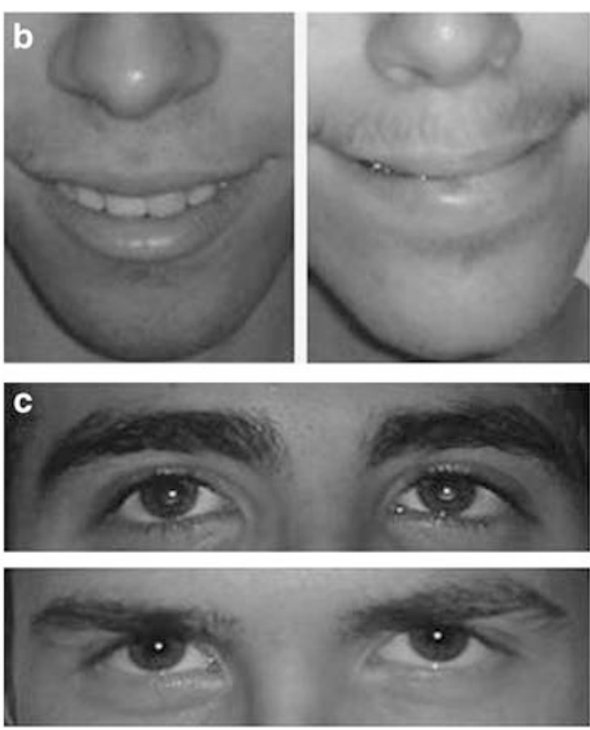

Figure 1 Facial appearance patients carrying the Xq26 duplication showing: (a) low set and small ears, (b) pointed chin, everted lower lip, (c) down-slanting palpebral fissures and narrow nasal bridge.

Table 1 Summary of the clinical features of patients carrying Xq26.2-q26.3 duplications

\begin{tabular}{|c|c|c|c|c|c|c|c|c|c|}
\hline Reference & $\operatorname{Dup}(X q)^{a}$ & $M R$ & Microcephaly & $\begin{array}{c}\text { Growth } \\
\text { delay }\end{array}$ & Hypotonia & Hypopituitarism & $\begin{array}{l}\text { Spina } \\
\text { bifida }\end{array}$ & Cryptorchidism & Others \\
\hline \multirow[t]{2}{*}{ This article } & Xq26.2-Xq26.3 & + & - & + & + & - & - & - & \multirow{2}{*}{$\begin{array}{l}\text { Dolichocephaly, dental malocclusion, } \\
\text { asymmetric lateral ventricles }\end{array}$} \\
\hline & Xq26.2-Xq26.3 & + & - & + & + & - & - & - & \\
\hline \multirow[t]{2}{*}{$\mathrm{Hol}$ et al. ${ }^{13}$} & Xq26-Xq27 & + & - & - & + & + & + & - & \multirow{2}{*}{$\begin{array}{l}\text { Hypoglycemia, hypertelorism, } \\
\text { myelomeningocele }\end{array}$} \\
\hline & Xq26-Xq27 & + & + & + & + & + & - & - & \\
\hline Solomon et al. ${ }^{16}$ & Xq26.3-Xq27.1 & $-{ }^{\mathrm{b}}$ & - & + & - & + & - & - & - \\
\hline Gecz et al. ${ }^{37}$ & Xq26-Xq28 & + & + & + & + & - & - & + & $\begin{array}{l}\text { Feeding problems, hypoglycemia, } \\
\text { conductive hearing loss, hypertelorism, obesity }\end{array}$ \\
\hline Mohandas et al. ${ }^{39}$ & Xq26.3-qter & + & NA & NA & NA & NA & NA & NA & - \\
\hline \multirow[t]{2}{*}{ Vasquez et al. ${ }^{10}$} & Xq26.3-qter & + & + & + & + & NA & - & + & \multirow[t]{2}{*}{-} \\
\hline & Xq26.3-qter & + & + & + & + & & - & + & \\
\hline Akiyama et al. ${ }^{15}$ & Xq26.3-qter & + & + & + & + & NA & - & + & $\begin{array}{l}\text { Palatal anomaly, agenesis of } \\
\text { the corpus callosum }\end{array}$ \\
\hline $\begin{array}{l}\text { Lagerström-Fermér } \\
\text { et al. }{ }^{12}\end{array}$ & Xq26.1-Xq27.3 & + & - & + & - & + & - & - & $\begin{array}{l}\text { Delayed pubertal development, } \\
\text { growth hormone deficiency }\end{array}$ \\
\hline
\end{tabular}

+ , present; -, not present; NA, data not available.

${ }^{a} A$ schematic comparison of duplication size is shown in Figure 3.

bHas received special education for learning problems. 
everted lower lip, malar hypoplasia and clinodactyly (Figure 1). Reflexes, strength, motility, walking and sensitivity were normal. The patient also presented with general hypotonia and mild muscular hypotrophy. Electroencephalogram did not show any alteration. Biochemistry results were normal for CK, TSH and free T4. Clinical, cardiological, digestive and ophthalmological examinations were normal, except for a mild growth delay and short stature. No IQ tests were performed, although there was an intellectual disability of $33 \%$, as defined by the Elderly and Social System Institute of Spain. At this moment, the patient had psychomotor developmental delay, remarkable general muscular hypotrophy (with CK value between reference ranges) and dysmorphic features, including an elongated and triangular face, with malar flattening and narrow nasal bridge. Table 1 summarizes clinical features of patients carrying different Xq26.2q26.3 duplications.

Patient 2. The younger brother is a 16-year old, who was born preterm (35 weeks gestation) with oligohydramnios, having a birth

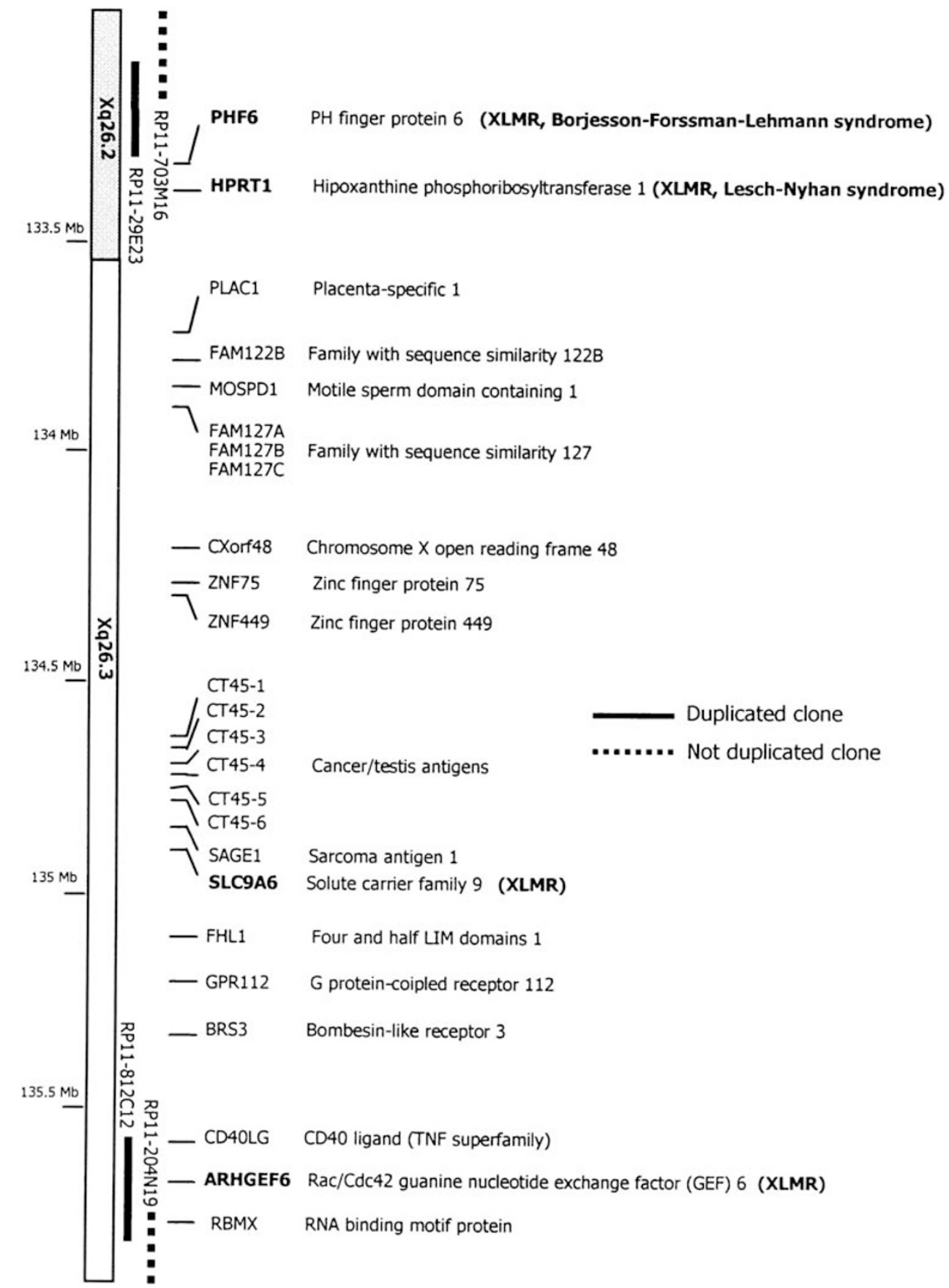

Figure 2 Diagram of the Xq26.2-Xq26.3 region, showing known genes (XLMR genes are in bold) according to the hg17 assembly of the UCSC (http:// genome.ucsc.edu/cgi-bin/hgGateway). Flanking normal clones are shown in dotted line (RP11-703M16 and RP11-204N19), whereas first and last duplicated clones are represented with a continuous line (RP11-29E23 and RP11-812C12). Note that RP11-29E23 clone is not overlapping any known gene, whereas the RP11-812C12 clone overlaps ARHGEF6 and RBMX. 
weight of $1440 \mathrm{~g}$ ( $>3$ centile $<10$ centile). Clinical examination when he was 8 years old showed an inexpressive long face with downslanting palpebral fissures, dental malocclusion, pointed chin, narrow nasal bridge, malar hypoplasia, everted lower lip and long philtrum (Figure 1). Reflexes, strength, motility, walking and sensitivity were normal. Trunk-evoked auditory potentials were also normal. Nonverbal IQ tests showed results within normal range, although learning was delayed. At 13 years of age, he underwent a new more complete IQ, which showed a moderate cognitive disability (full-scale IQ 61, verbal IQ 54, performance IQ 80). At this moment, he had psychomotor developmental delay, remarkable general muscular hypotrophy (with CK values between reference ranges).

\section{Molecular analyses}

Previous MLPA and fluorescence in situ hybridization analyses showed a duplication encompassing the ARHGEF6 gene, both in the patients and the mother. Fluorescence in situ hybridization with BACs of the region showed a tandem duplication (for further details see Madrigal et $\left.a^{3}{ }^{3}\right)$. By $\mathrm{X}$-chromosome aCGH, a $2.8 \mathrm{Mb}$ duplication at Xq26.2-q26.3 was identified (arr Xq26.2q26.3(133133901x1,13321785$135693617 \times 2,135914669 x 1) m a t)$. The duplication involved 28 contiguous BAC clones that overlapped 24 genes. First and last duplicated clones were RP11-29E23 and RP11-812C12, respectively, and flanking normal clones were RP11-703M16 and RP11-204N19 (Figure 2). The RP11-29E23 clone was not overlapping any known gene, whereas the RP11-812C12 clone overlapped the ARHGEF6 and RBMX genes. qPCR analysis showed normal dosage for fist exon of RBMX gene and an extra copy of last exon of ARHGEF6 gene, which confirmed ARHGEF6 duplication. MLPA confirmed the presence of the duplication in the mother, and $\mathrm{X}$-chromosome inactivation studies for $A R$ and FMR1 loci showed a complete skewed X-inactivation pattern.

\section{DISCUSSION}

Men with duplications within the long arm of the X chromosome are rare and most cases are inherited from a maternal heterozygote. ${ }^{20,21}$ Although data regarding $\mathrm{Xq}$ duplications in men are limited, a clear pattern of characteristic features can be discerned. Mental, psychomotor and growth retardation as well as craniofacial anomalies, hypotonia, hypoplastic genitalia, spina bifida and feeding difficulties are significant issues in individuals carrying Xq26-q27 duplications. ${ }^{10,12-16}$ Cryptorchidism is an additional clinical feature present in patients with larger duplications that affect Xq28 region (Table 1; Figure 3), which suggests that the gene responsible for this pathology might be located at the $\mathrm{Xq} 28$.

Given the relatively small size of the duplication we present here, it could help to identify the genes responsible for the phenotype associated with distal Xq duplications. Several genes map within this region including four X-linked MR genes: ARHGEF6, PHF6, HPRT1 and SLC9A6. Although we cannot say which genes are responsible for the phenotype, it seems clear that, similarly to what happens with PLP1 and MECP2 genes, ${ }^{22,23}$ the excess of one or more of these genes could be responsible for MR. Clinical features associated to the duplication are different to those associated to the haploinsufficiency of these genes. ${ }^{24-27}$

ARHGEF6 (OMIM *300267) encodes for a Rho guanine nucleotide exchange factor, which is mainly expressed in the central nervous system, and belongs to a family of cytoplasmic proteins that activate the Ras-like family of Rho proteins by exchanging bound GDP for GTP. ${ }^{28}$ Most proteins of this family function as molecular switches, cycling between an inactive state, linked to the GDP, and an active state, combined with GTP. Mutations in this gene are responsible for nonsyndromic forms of XLMR. ${ }^{24}$ ARHGEF6 is involved in the same signaling module that $P A K 3$, thereby regulating spine morphogenesis and plasticity of synaptic networks. The sequential implication of $P A K 3$ in spine morphogenesis has been recently proposed as a possible biological mechanism underlying MR associated to mutations of these genes. ${ }^{29}$ qPCR results showed the entire gene was within the duplication, thus discarding disruption of ARHGEF6 as an effect of the duplication. The second gene, PHF6 (OMIM *300414), encodes for a protein with two zinc-finger domains with a potential role in transcription regulation. ${ }^{30}$ Mutations in PHF6 are associated with Borjeson-Forssman-Lehmann syndrome (OMIM \#301900), which is characterized by MR, epilepsy, hypogonadism, obesity and minor dimorphisms, such as long ears or wide palpebral fissures. ${ }^{25,31}$ PHF6 is expressed in many adult organs mainly including brain, spleen, kidney and the epithelial component of teeth. The HPRT1 gene (OMIM *308000) encodes for an enzyme, which is important in the generation of purine nucleotides through the purine salvage pathway. ${ }^{32}$ This gene is responsible for the Lesch-Nyhan syndrome (OMIM \#300322), an inherited metabolic disorder characterized by metabolic and neurological dysfunctions. Main clinical features are MR, spastic cerebral palsy, choreoathetosis, uric acid urinary stones, and self-destructive biting of fingers and lips. ${ }^{26}$ Finally, the SLC9A6 gene (OMIM *300231) encodes for a monovalent sodium-selective sodium/hydrogen exchanger, which regulates endosomal $\mathrm{pH}$ and $\mathrm{Na}^{+}$concentrations. ${ }^{33,34}$ SLC9A6 mutations have been recently reported to be associated with microcephaly, seizures, ataxia and absent speech. ${ }^{27}$

Two pathologies that have been associated to this region are hypopituitarism and spina bifida. Because our patients do not show any of them, gene loci for these clinical traits must be located outside the duplicated region. The gene SOX3 that maps at Xq27.1 has been pointed out as a candidate gene for X-linked hypopituitarism in patients with duplications that include Xq27.12-14,35,36 Nevertheless, there

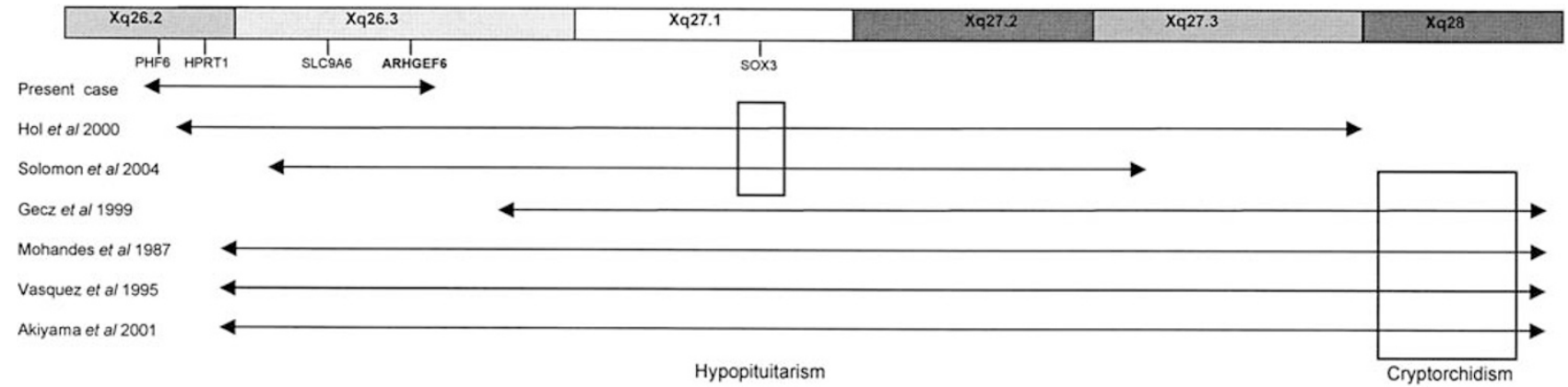

Figure 3 Comparison of patients with reported duplications involving the Xq26 region. Cytogenetic bands are shown for Xq26.2 to Xqter, and the location of the specific genes discussed in the text is also shown, according to the hg17 assembly of the UCSC (http://genome.ucsc.edu/cgi-bin/hgGateway). Boxes indicate candidate regions for cryptorchidism and hypopituitarism. 
are patients carrying Xq27 duplications who do not present hypopituitarism, ${ }^{15,37}$ which may be explained by hypopituitarism presenting with incomplete penetrance, or by the lack of diagnosis. Regarding spina bifida, accepting that there is a causative gene for this trait in the long arm of the $\mathrm{X}$ chromosome, some authors narrowed the critical region to Xq26.2 [16], which is not in agreement with our findings.

In men, X-chromosome duplications lead to functional disomy of genes located within the duplicated region. In contrary, women carrying tandem duplications are usually phenotypically normal, as these structural abnormalities result in skewed patterns of inactivation, with the abnormal $\mathrm{X}$ chromosome being inactivated in the majority of cells. ${ }^{38}$ Here, the carrier mother had neither clinical signs, nor learning difficulties, which may be explained by a skewed X-inactivation pattern $(90 / 10)$ of the aberrant $\mathrm{X}$ chromosome, although the $A R$ and the duplicated region were far apart, and thus, a recombination event cannot be fully excluded.

To conclude, we highlight the importance of reporting X-chromosome microduplications, as the phenotypic repercussion of increased gene dosage of X-linked genes remains mostly unknown and their clinical and molecular characterization will shed more light into the phenotypic implication of functional disomy of X-chromosome genes, and into the identification of new syndromes.

\section{ACKNOWLEDGEMENTS}

We thank Fundación Ramón Areces (V-2006-FRARECES) and all members of this family for their cooperation. The 'CIBER de Enfermedades Raras' is an initiative of the ISCIII. We thank Dr Beatriz Gómez for revising the clinical section of the article.

1 Shaw-Smith, C., Redon, R., Rickman, L., Rio, M., Willatt, L., Fiegler, H. et al. Microarray based comparative genomic hybridisation (array-CGH) detects submicroscopic chromosomal deletions and duplications in patients with learning disability/ mental retardation and dysmorphic features. J. Med. Genet. 41, 241-248 (2004).

2 Madrigal, I., Rodriguez-Revenga, L., Armengol, L., Gonzalez, E., Rodriguez, B., Badenas, C. et al. X-chromosome tiling path array detection of copy number variants in patients with chromosome X-linked mental retardation. BMC Genomics 8, 443 (2007).

3 Madrigal, I., Rodriguez-Revenga, L., Badenas, C., Sanchez, A., Martinez, F., Fernandez, I. et al. MLPA as first screening method for the detection of microduplications and microdeletions in patients with X-linked mental retardation. Genet. Med. 9, 117-122 (2007).

4 Froyen, G., Van Esch, H., Bauters, M., Hollanders, K., Frints, S. G., Vermeesch, J. R. et al. Detection of genomic copy number changes in patients with idiopathic mental retardation by high-resolution $\mathrm{X}$-array-CGH: important role for increased gene dosage of XLMR genes. Hum. Mutat. 28, 1034-1042 (2007).

5 Lugtenberg, D., de Brouwer, A. P., Kleefstra, T., Oudakker, A. R., Frints, S. G., SchranderStumpel, C. T. et al. Chromosomal copy number changes in patients with non-syndromic $X$ linked mental retardation detected by array CGH. J. Med. Genet. 43, 362-370 (2006).

6 Steinbach, P., Horstmann, W. \& Scholz, W. Tandem duplication dup(X)(q13q22) in a male proband inherited from the mother showing mosaicism of $\mathrm{X}$-inactivation. Hum. Genet. 54, 309-313 (1980).

7 Thode, A., Partington, M. W., Yip, M. Y., Chapman, C., Richardson, V. F. \& Turner, G. A new syndrome with mental retardation, short stature and an Xq duplication. Am. J. Med. Genet. 30, 239-250 (1988)

8 Schmidt, M., Du Sart, D., Kalitsis, P., Leversha, M., Dale, S., Sheffield, L. et al. Duplications of the $X$ chromosome in males: evidence that most parts of the $X$ chromosome can be active in two copies. Hum. Genet. 86, 519-521 (1991).

9 Muscatelli, F., Verna, J. M., Philip, N., Moncla, A., Mattei, M. G., Mattei, J. F. et al. Physical mapping of an Xq-proximal interstitial duplication in a male. Hum. Genet. 88, 691-694 (1992).

10 Vasquez, A. I., Rivera, H., Bobadilla, L. \& Crolla, J. A. A familial Xp+ chromosome, dup (Xq26.3-> qter). J. Med. Genet. 32, 891-893 (1995).

11 Novelli, A., Bernardini, L., Salpietro, D. C., Briuglia, S., Merlino, M. V., Mingarelli, R. et al. Disomy of distal Xq in males: case report and overview. Am. J. Med. Genet. A 128A, 165-169 (2004).

12 Lagerstrom-Fermer, M., Sundvall, M., Johnsen, E., Warne, G. L., Forrest, S. M., Zajac, J. D. et al. X-linked recessive panhypopituitarism associated with a regional duplication in Xq25-q26. Am. J. Hum. Genet. 60, 910-916 (1997).

$13 \mathrm{Hol}$, F. A., Schepens, M. T., van Beersum, S. E., Redolfi, E., Affer, M., Vezzoni, P. et al. Identification and characterization of an Xq26-q27 duplication in a family with spina bifida and panhypopituitarism suggests the involvement of two distinct genes. Genomics 69, 174-181 (2000).

14 Lachlan, K. L., Collinson, M. N., Sandford, R. O., van Zyl, B., Jacobs, P. A. \& Thomas, N. S. Functional disomy resulting from duplications of distal $\mathrm{Xq}$ in four unrelated patients. Hum. Genet. 115, 399-408 (2004).

15 Akiyama, M., Kawame, H., Ohashi, H., Tohma, T., Ohta, H., Shishikura, A. et al. Functional disomy for Xq26.3-qter in a boy with an unbalanced $t(X ; 21)(q 26.3 ; p 11.2)$ translocation. Am. J. Med. Genet. 99, 111-114 (2001).

16 Solomon, N. M., Ross, S. A., Forrest, S. M., Thomas, P. Q., Morgan, T., Belsky, J. L. et al. Array comparative genomic hybridisation analysis of boys with $\mathrm{X}$-linked hypopituitarism identifies a $3.9 \mathrm{Mb}$ duplicated critical region at Xq27 containing SOX3. J. Med. Genet. 44, e75 (2007).

17 Madrigal, I., Carrio, A., Gomez, C., Rozman, M., Esteve, J., Nomdedeu, B. et al. Fluorescence in situ hybridization studies using BAC clones of the EVI1 locus in hematological malignancies with $3 q$ rearrangements. Cancer Genet. Cytogenet. 170, 115-120 (2006).

18 Rodriguez-Revenga, L., Madrigal, I., Badenas, C., Xuncla, M., Jimenez, L. \& Mila, M. Premature ovarian failure and fragile $X$ female premutation carriers: no evidence for a skewed X-chromosome inactivation pattern. Menopause 16, 944-949 (2009).

19 Carrel, L. \& Willard, H. F. An assay for X inactivation based on differential methylation at the fragile X locus, FMR1. Am. J. Med. Genet. 64, 27-30 (1996).

20 Zhang, A., Weaver, D. D. \& Palmer, C. G. Molecular cytogenetic identification of four X chromosome duplications. Am. J. Med. Genet. 68, 29-38 (1997).

21 Cheng, S. F., Rauen, K. A., Pinkel, D., Albertson, D. G. \& Cotter, P. D. Xq chromosome duplication in males: clinical, cytogenetic and array CGH characterization of a new case and review. Am. J. Med. Genet. A 135, 308-313 (2005).

22 Lugtenberg, D., Kleefstra, T., Oudakker, A. R., Nillesen, W. M., Yntema, H. G. Tzschach, A. et al. Structural variation in Xq28: MECP2 duplications in $1 \%$ of patients with unexplained XLMR and in $2 \%$ of male patients with severe encephalopathy. Eur. J. Hum. Genet. 17, 444-453 (2009).

23 Wolf, N. I., Sistermans, E. A., Cundall, M., Hobson, G. M., Davis-Williams, A. P., Palmer, R. et al. Three or more copies of the proteolipid protein gene PLP1 cause severe Pelizaeus-Merzbacher disease. Brain 128, 743-751 (2005).

24 Kutsche, K., Yntema, H., Brandt, A., Jantke, I., Nothwang, H. G., Orth, U. et al. Mutations in ARHGEF6, encoding a guanine nucleotide exchange factor for Rho GTPases, in patients with X-linked mental retardation. Nat. Genet. 26, 247-250 (2000).

25 Carter, M. T., Picketts, D. J., Hunter, A. G. \& Graham, G. E. Further clinical delineation of the Borjeson-Forssman-Lehmann syndrome in patients with PHF6 mutations. Am. J. Med. Genet. A 149A, 246-250 (2009).

26 Tvrdik, T., Marcus, S., Hou, S. M., Falt, S., Noori, P., Podlutskaja, N. et al. Molecular characterization of two deletion events involving Alu-sequences, one novel base substitution and two tentative hotspot mutations in the hypoxanthine phosphoribosyltransferase (HPRT) gene in five patients with Lesch-Nyhan syndrome. Hum. Genet. 103, 311-318 (1998).

27 Gilfillan, G. D., Selmer, K. K., Roxrud, I., Smith, R., Kyllerman, M., Eiklid, K. et al. SLC9A6 mutations cause X-linked mental retardation, microcephaly, epilepsy, and ataxia, a phenotype mimicking Angelman syndrome. Am. J. Hum. Genet. 82, 1003-1010 (2008).

28 Bourne, H. R., Sanders, D. A. \& McCormick, F. The GTPase superfamily: a conserved switch for diverse cell functions. Nature 348, 125-132 (1990).

29 Node-Langlois, R., Muller, D. \& Boda, B. Sequential implication of the mental retardation proteins ARHGEF6 and PAK3 in spine morphogenesis. J. Cell Sci. 119, 4986-4993 (2006).

30 Lower, K. M., Turner, G., Kerr, B. A., Mathews, K. D., Shaw, M. A., Gedeon, A. K. et al. Mutations in PHF6 are associated with Borjeson-Forssman-Lehmann syndrome. Nat. Genet. 32, 661-665 (2002).

31 Borjeson, M., Forssman, H. \& Lehmann, O. An X-linked, recessively inherited syndrome characterized by grave mental deficiency, epilepsy, and endocrine disorder. Acta. Med. Scand. 171, 13-21 (1962).

32 Keebaugh, A. C., Sullivan, R. T. \& Thomas, J. W. Gene duplication and inactivation in the HPRT gene family. Genomics 89, 134-142 (2007).

33 Wakabayashi, S., Shigekawa, M. \& Pouyssegur, J. Molecular physiology of vertebrate $\mathrm{Na}+\mathrm{H}+$ exchangers. Physiol. Rev. 77, 51-74 (1997).

34 Counillon, L. \& Pouyssegur, J. The expanding family of eucaryotic $\mathrm{Na}(+) / \mathrm{H}(+)$ exchangers. J. Biol. Chem. 275, 1-4 (2000).

35 Laumonnier, F., Ronce, N., Hamel, B. C., Thomas, P., Lespinasse, J., Raynaud, M. et al. Transcription factor SOX3 is involved in X-linked mental retardation with growth hormone deficiency. Am. J. Hum. Genet. 71, 1450-1455 (2002).

36 Woods, K. S., Cundall, M., Turton, J., Rizotti, K., Mehta, A., Palmer, R. et al. Over- and underdosage of SOX3 is associated with infundibular hypoplasia and hypopituitarism. Am. J. Hum. Genet. 76, 833-849 (2005).

37 Gecz, J., Baker, E., Donnelly, A., Ming, J. E., McDonald-McGinn, D. M., Spinner, N. B. et al. Fibroblast growth factor homologous factor 2 (FHF2): gene structure, expression and mapping to the Borjeson-Forssman-Lehmann syndrome region in Xq26 delineated by a duplication breakpoint in a BFLS-like patient. Hum. Genet. 104, 56-63 (1999).

38 Plenge, R. M., Stevenson, R. A., Lubs, H. A., Schwartz, C. E. \& Willard, H. F. Skewed $\mathrm{X}$-chromosome inactivation is a common feature of $\mathrm{X}$-linked mental retardation disorders. Am. J. Hum. Genet. 71, 168-173 (2002).

39 Mohandas, T., Geller, R. L., Yen, P. H., Rosendorff, J., Bernstein, R., Yoshida, A et al. Cytogenetic and molecular studies on a recombinant human $\mathrm{X}$ chromosome: implications for the spreading of $X$ chromosome inactivation. Proc. Natl Acad. Sci. USA 84, 4954-4958 (1987). 